\title{
Aplikasi Mobile Housekeeping Asisten Rumah Kita (ARUMI) Berbasis iOS
}

\author{
Agustinus Dwiutomo Pristya Putra, Risna Sari \\ Program Studi Teknik Informatika \\ Jurusan Teknik Informatika dan Komputer \\ Politeknik Negeri Jakarta \\ gustin.putra@gmail.com, risna.sari@tik.pnj.ac.id
}

Diterima: 16 Agustus 2017. Disetujui: 12 September 2017. Dipublikasikan: November 2017

\begin{abstract}
Abstrak - Saat ini masyarakat masih kesulitan mencari tenaga yang dapat membantu menyelesaikan perkerjaan rumah tangga mereka dengan instan, cepat, dan murah. Permasalahan tersebut timbul akibat tidak adanya teknologi yang dapat menghubungkan antara penyedia layanan jasa dengan masyarakat umum secara luas sehingga pihak penyedia layanan jasa kesulitan menawarkan layanan dan sebaliknya pihak masyarakat umum juga kesulitan untuk memesan layanan jasa. Oleh sebab itu dibangun sebuah aplikasi mobile houskeeping berbasis iOS untuk perangkat iphone yang dapat digunakan untuk memfasilitasi perusahaan layanan jasa housekeeping untuk dapat menawarkan layanan jasa dengan mudah serta dapat menghubungkan perusahaan penyedia layanan jasa dengan masyarakat umum secara luas. Dalam implementasinya, juga dibangun backend petugas yang terkoneksi langsung dengan aplikasi pada perangkat iOS dengan menggunakan API dan menggunakan Database MySQL. Metode yang digunakan pada penelitian ini ialah metode GRAPPLE (Guidelines for Rapid APPlication Engineering) dengan dasar terori Unified Model Languange (UML). Dengan dibuatnya aplikasi ini maka bisa menjadi solusi yang dapat memfasilitasi dan menghubungkan antara perusahaan penyedia layanan jasa dengan masyarakat secara umum.
\end{abstract}

Kata Kunci : aplikasi mobile housekeeping, grapple, unified model langunge.

\section{PENDAHULUAN}

Perkembangan teknologi yang semakin pesat saat ini telah membuat banyak perubahan dalam gaya hidup masyarakat. Salah satu perubahannya adalah banyaknya penggunaan smartphone, Para pengguna smartphone berasal dari berbagai kalangan dan umur. Penggunaannya bisa berupa browsing, e-mail, bermain game, dan yang sedang marak saat ini layanan pemesanan jasa. Dalam industri sistem operasi perangkat mobile, dua sistem operasi yang paling banyak digunakan adalah android dan iOS[1].
Berdasarkan data yang didapatkan dari MarketShare pada kuartal ke tiga tahun 2015 yang dirilis oleh Nielsen Company, ju mlah pengguna iOS di Indonesia adalah sebesar 42,7 \% sedangkan pengguna android adalah sebesar 52,6 \% dari seluruh pengguna sistem operasi perangkat mobile sehingga sangat penting untuk membuat aplikasi dalam 2 jenis platform sistem operasi tersebut[1].

Aplikasi ARUMI dibuat dengan didasari dari pengamatan bahwa masyarakat masih kesulitan mencari tenaga kerja yang dapat membantu menyelesaikan perkerjaan rumah tangga dengan cepat, dan murah. Permasalahan tersebut timbul akibat tidak adanya teknologi yang dapat menghubungkan antara penyedia layanan jasa dengan masyarakat umum secara luas sehingga pihak penyedia layanan jasa kesulitan menawarkan layanan dan sebaliknya pihak masyarakat umum juga kesulitan untuk memesan layanan jasa.

Sementara itu, dilakukan juga wawancara secara khusus dengan pelaku industri kontraktor jasa kebersihan yaitu PT Karya Konsulindo Bersama dan dapat disimpulkan bahwa mereka mengalami kesulitan untuk menawarakan layanan Housekeeping yang dapat menjangkau seluruh lapisan masyarakat secara efektif. Oleh sebab itu keberadaan aplikasi jasa Housekeeping begitu penting dan besar peranannya untuk dapat memfasilitasi dan menghubungkan antara perusahaan layanan jasa housekeeping dengan masyarakat.

\section{METODE PENGEMBANGAN SISTEM}

Metode yang dipilih untuk pembuatan dan pengembangan menggunakan GRAPPLE (Guidelines for Rapid APPlication Engineering). Pemilihan metode ini bertujuan agar dapat menghasilkan sistem berorientasi objek dalam waktu yang singkat tanpa mengurangi kualitas sistem yang dibangun. GRAPPLE adalah sebuah pemodelan proses dalam pengembangan software yang menekankan pada segmen-segmen yang 
dilakukan pada seju mlah tahapan, setiap tahap akan menghasilkan produk kerja dengan bentuk yang berorientasi objek[2]. Tahapan yang terdapat dalam GRAPPLE tidak disusun dalam bentuk yang statis sehingga setiap tahap dapat dikerjakan berulang kali dengan urutan kerja yang tidak sesuai dengan urutan yang ada. Tahap-tahap yang digunakan dalam GRAPPLE mencakup analisis kebutuhan sistem, pengembangan model dan diagram, pembuatan kode hingga tahap instalasi dan evaluasi yang dijelaskan dibawah ini [2]:

\section{a. Requirement Gathering}

Dalam tahapan ini dilakukan wawancara dan diskusi dengan pelaku industri houekeeping untuk merumuskan masalah dan kendala yang dihadapi oleh pelaku industri jasa Housekeeping dalam menawarkan layanan jasa kepada masyarakat umum.

b. Analysis

Melakukan analisa terhadap manfaat dan dampak positif yang dihasilkan bagi perusahaan dan masyarakat secara umum dari pembuatan aplikasi in $\mathrm{i}$.

c. Design

Melakukan perancangan desain $U M L$ dan rancangan tampilan user interface yang disesuaikan dengan case dan requirement yang dibutuhkan oleh perusahaan penyedia layanan jasa Housekeeping.

d. Development

Melakukan pembuatan aplikasi meliputi pemrograman dan pembuatan desain tampilan antar muka yang dibuat sesuai dengan rancangan $U M L$ dan user interface yang sebelumnya telah dibuat pada tahap design.

e. Deployment

Melakukan penyebaran aplikasi dengan cara menawarkan aplikasi kepada perusahaan penyedia layanan jasa housekeeping dengan tujuan untuk dapat bekerjasama untuk mengimplemtasikan layanan yang ada sehingga aplikasi dapat digunakan oleh mas yarakat u mu m secara luas.

\section{PERANCANGAN DAN REALISASI}

\section{A. Requirement Gathering}

Dari hasil penelitian dan pengamatan penulis dapat disimpulkan beberapa kebutuhan dari user terkait, diantaranya [3]:

1. Functional Requirement

- Dapat melakukan registrasi akun baru pada halaman login ap likasi.

- Terdapat fitur map yang dapat menampilkan lokasi GPS user.
- Terdapat menu yang dapat menampilkan histori order transaksi user.

- Terdapat menu yang dapat digunakan oleh user untuk melakukan komplain atau menyampaikan keluhan

- Terdapat label harga layanan yang dapat menghitung harga sesuai dengan jenis dan detail layanan yang dipilih $u s e r$.

- Terdapat fitur navigasi pada halaman petugas.

- Terdapat fitur konfirmasi status order pada hala man petugas.

2. Non Functional Requirement

- Aplikasi ARUMI hanya dapat digunakan pada smartphone berbasis iOS seperti iphone, dan ipod.

- Halaman petugas / asisten hanya dapat diakses oleh petugas atau tenaga kerja yang telah terdaftar pada perusahaan.

- Halaman backend asisten dibuat berbasiskan website agar dapat diakses pada semua jenis perangkat apapun dengan mudah.

B. Analysis

Selama ini, jasa housekeeping sulit ditemukan dan dipesan khususnya untuk penggunaan secara pribadi atau rumah tangga. Hal ini disebabkan karena penyedia layanan masih menggunakan sistem konvensional sehingga sulit menjangkau masyarakat umum khususnya untuk kebutuhan rumah tangga.

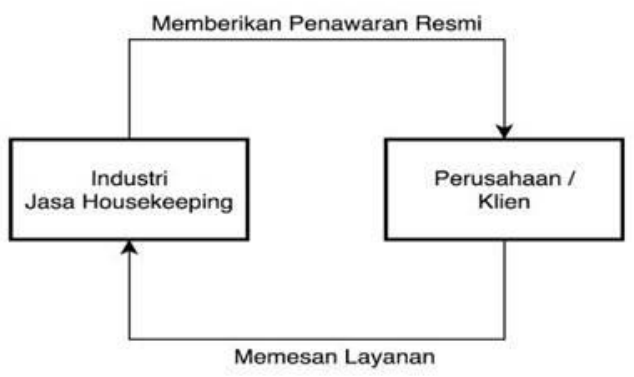

Gambar 1. Ilustrasi Proses Bisnis Industri Housekeeping Konvensional

Dalam proses pemesanan layanan jasa pada perusahaan housekeeping konvensional hanya terjadi hubungan bisnis dan pemesanan layan jasa antara penyedia jasa dengan perusahaan / klien. Tidak ada sebuah sistem yang dapat dijadikan penghubung yang dapat memfasilitasi perusahaan dan masyarakat atau individu rumah tangga untuk dapat berinteraksi dan menggunakan layanan dengan mudah. 


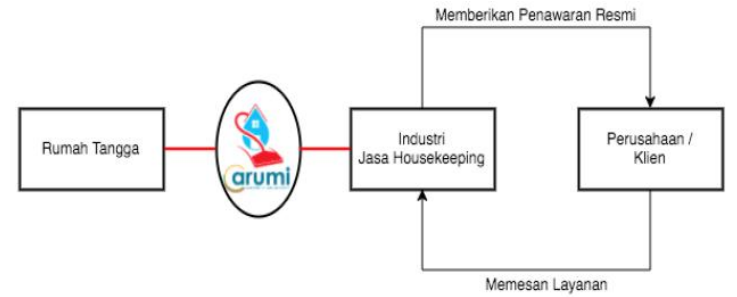

Gambar 2. Ilustrasi Proses Bisnis Industri Housekeeping dengan Arumi

Aplikasi ARUMI dapat dijadikan solusi untuk dapat memfasilitasi perusahaan penyedia layanan jasa housekeeping agar dapat terhubung dengan masyarakat umum dan masyarakat dapat memesan dan menggunakan layananan jasa dengan mudah melalui smarphone mereka masing-masing.

\section{Design}

Aplikasi ARUMI terbagi menjadi 2 bagian yaitu aplikasi frontend berbasis iOS, dan memiliki akun backend untuk halaman asisten team yang berbasis website. Untuk tahap desain mengacu pada referensi [4-5]:

1. Use Case Diagram

Hasil identifikasi kebutuhan sistem dapat dilihat seperti gambar use case diagram berikut :

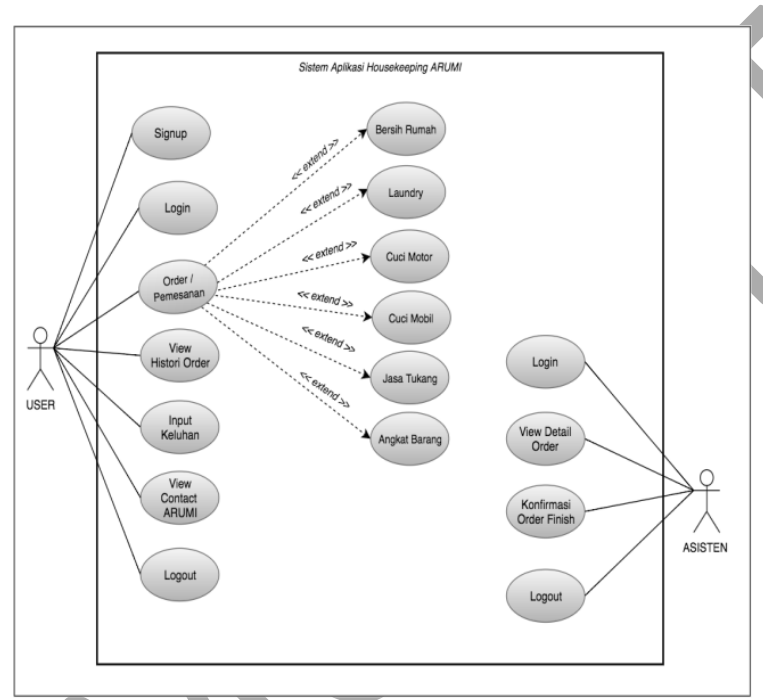

Gambar 3. Use Case Diagram Arumi

Berikut penjelasan dari aktor pada use case diagram aplikasi A RUMI:

TABEL 1. DESKRIPSI AKTOR USE CASE DIAGRAM

\begin{tabular}{|l|l|}
\hline \multicolumn{1}{|c|}{ Aktor } & \multicolumn{1}{c|}{ Description } \\
\hline User & $\begin{array}{l}\text { User merupakan pengguna aplikasi. } \\
\text { User dapat melakukan registrasi dan } \\
\text { pemesanan layanan. }\end{array}$ \\
\hline Asisten Team & $\begin{array}{l}\text { Asisten Team merupakan user yang } \\
\text { memiliki hak akses untuk melakukan }\end{array}$ \\
& $\begin{array}{l}\text { update terhadap status order apabila } \\
\text { order telah selesai diproses. Merupakan } \\
\text { aktor dari pihak perusahaan penyedia } \\
\text { layanan jasa housekeeping terkait. }\end{array}$ \\
\hline
\end{tabular}

Pada aplikasi ARUMI yang dibangun terdapat 2 aktor yaitu user dan asisten atau petugas ARUMI. User dapat mengakses aplikasi pada perangkat iOS, sedangkan Asisten / petugas mengkases pada halaman petugas yang berbasiskan website.

\section{Activity Diagram Pemesanan Layanan}

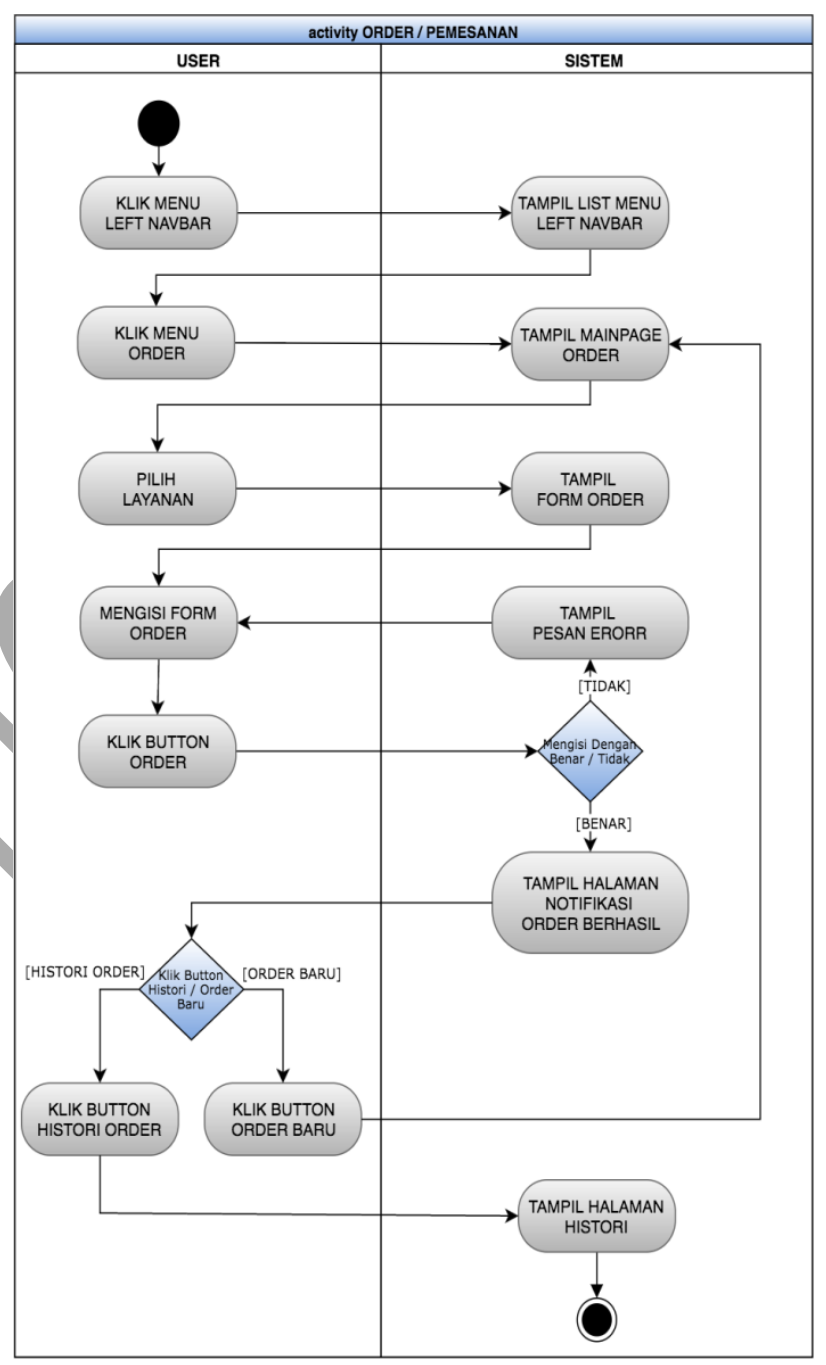

Gambar 4. Activity Diagram Arumi

Gambar 4 merupakan alur aktivitas dari proses pemesanan layanan jasa pada aplikasi yang dilakukan oleh user.

Tahapan dimulai dari melakukan klik pada menu left navbar, kemudian user memilih menu order. Setelah itu, aplikasi akan menampilkan halaman main page yang berisikan pilihan jen is layanan. Setelah user memilih salah satu dari layanan yang hendak dipesan maka akan tampil form pemesanan yang selanjutnya wajib di input oleh user. Setelah form selesai di input maka user akan menekan button order dan apabila data order 
berhasil tersimpan maka akan tampil halaman notifikasi order berhasil dilaku kan.

\section{Class Diagram}

Class model dari aplikasi A RUMI terga mbar pada Gambar 5.

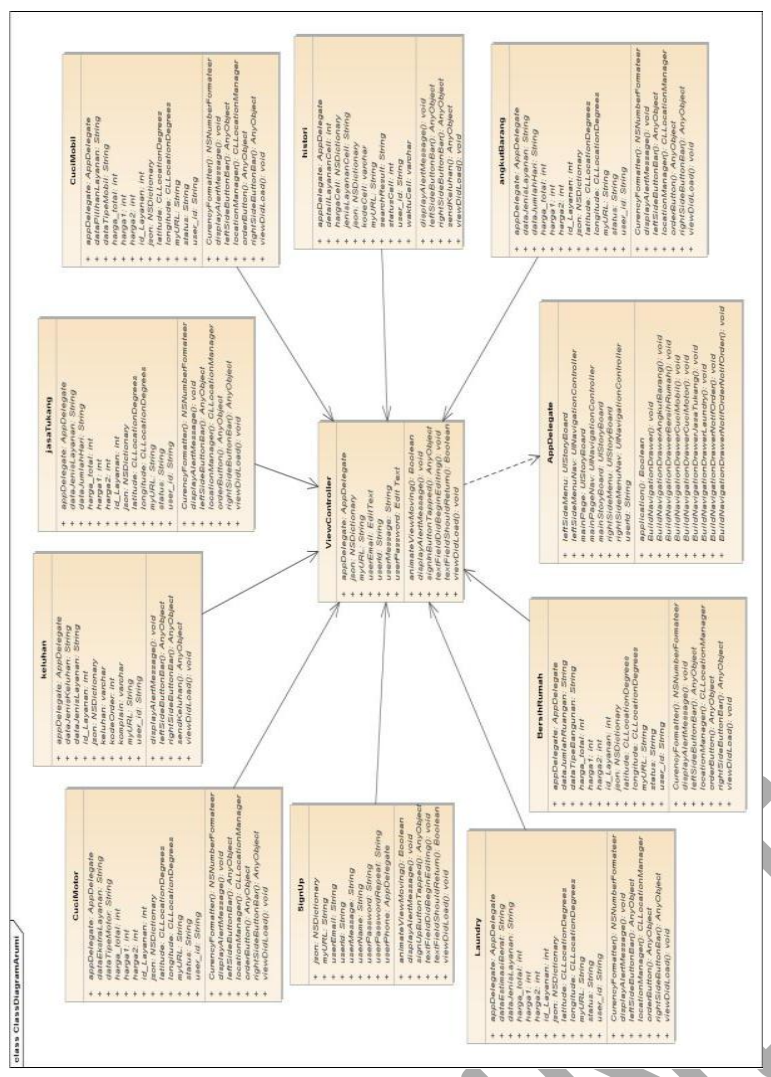

Gambar 5. Class Diagram ARUMI

Pada Gambar 5 tergambar class model atau class diagram. Diagram ini telah dilengkapi dengan operation pada objek class yang ada. Sesuai dengan apa yang dilakukan oleh sistem terhadap objekobjek kelas dan hubungan antara kelas-kelas yang ada.

4. Sequence Diagram Pemesanan Layanan

Pada Gambar 6 menggambarkan sequence diagram pada proses pemesanan layanan jasa housekeeping yang terdapat pada aplikasi ARUMI.

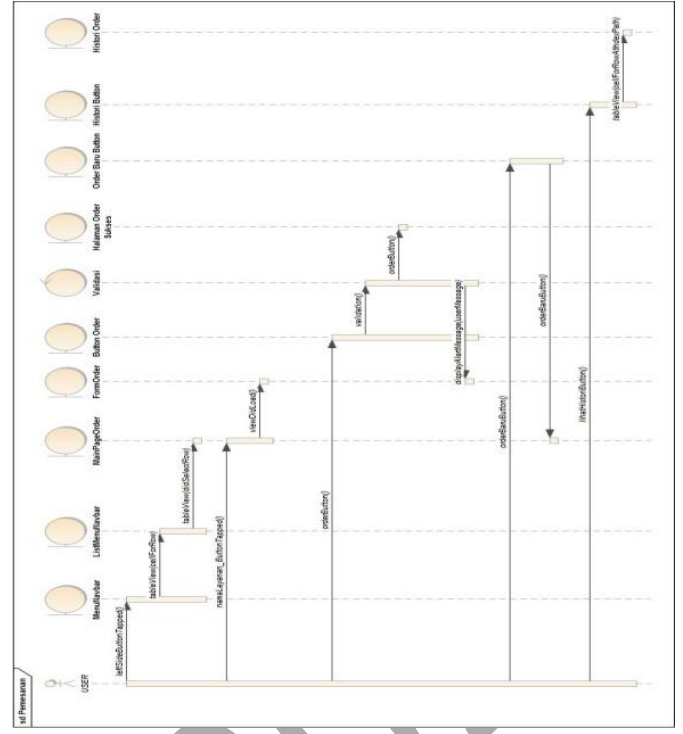

Gambar 6. Sequence Diagram Kontribusi Donasi

\section{Perancangan Data}

Perancangan data sistem menggunakan Entity Relationship Diagram[6]. ERD dirancang berdasarkan kebutuhan basis data dari aplikasi ARUMI.

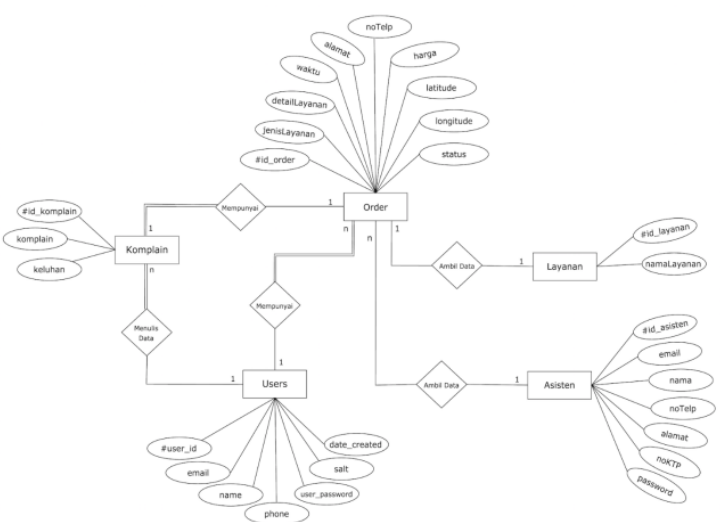

Gambar 7. Entity Relationship Diagram (ERD)

D. Realisasi Tampilan User Interface Aplikasi Setelah melakukan proses Login, aplikasi akan menampilkan halaman utama/ home page yang berisi pilihan layanan jasa yang dapat dipesan[7].

Gambar 8 adalah tampilan halaman main page aplikasi ARUMI, pada halaman ini ditampilkan pilihan layanan jasa yang ditawarkan, kemudian user dapat memilih layanan yang hendak dipesan dan selanjutnya user akan dialihkan ke halaman pemesanan. 


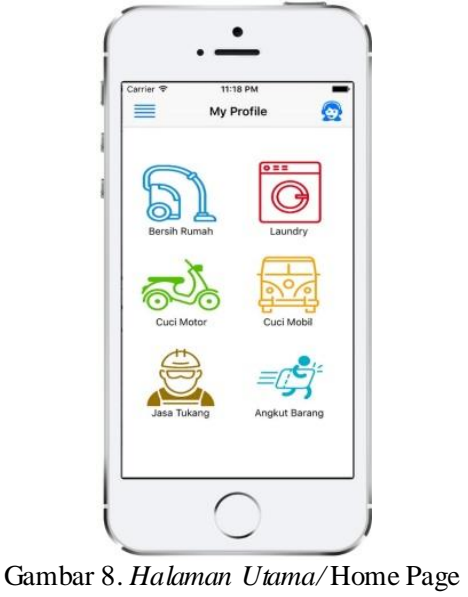

Gambar 9 dan 10 adalah tampilan halaman order/pemesanan layanan pada aplikasi ARUMI, pada halaman in i akan ditampilkan lokasi user pada map berdasarkan lokasi GPS pada perangkat iphone user. Selain itu juga akan ditampilkan form pemesanan yang dapat diisi bila ingin melakukan pemesanan. Pada halaman ini juga akan ditampilkan perhitungan harga berdasarkan layanan yang dipilih oleh user.

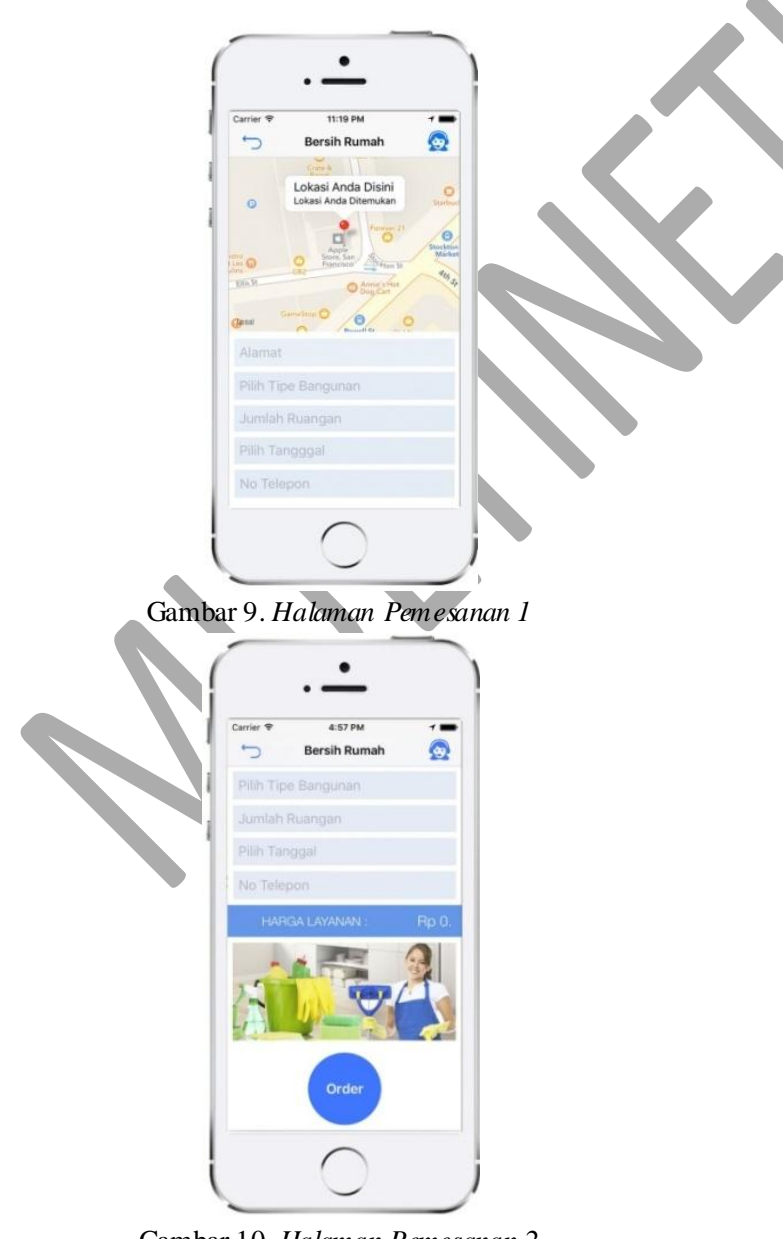

Gambar 10. Halaman Pemesanan 2

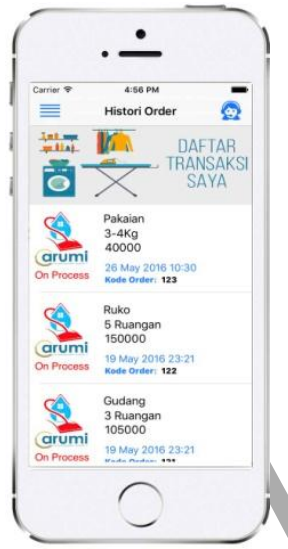

Gambar 11. Halaman Histori Order

E. Analisis Data / Evaluasi Pengujian Black Box Setelah dilakukan pengujian terhadap aplikasi ARUMI dapat diketahui bahwa semua fungsi dan fitur aplikasi dapat berjalan dengan baik dan mendapat respons positif dari pihak perusahaan-perusahaan penyedia layanan housekeeping. Semua fungsi berjalan sesuai dengan user requirement yang dibutuhkan tanpa ada kendala. Pemesanan layanan di dalam aplikasi juga dapat dilakukan dengan mudah dan memiliki tampilan yang user friendly dan simpel sehingga aplikasi sangat mudah digunakan oleh user. Dengan adanya ARUMI dapat memudahkan hubungan antara perusahaan penyedia jasa dengan pengguna individu rumah tangga sehingga dapat saling menguntungkan dapat membantu untuk menyelesaikan permasalahan terkait dengan pekerjaan rumah tangga pada masyarakat modern.

Pengolahan data-data pada aplikasi yang meliputi koneksi antara input data yang dilakukan user pada aplikasi juga dapat terkoneksi dengan database online serta dapat terintegrasi dengan aplikasi lain yang dijalan kan dengan platform selain iOS. Hal ini tentu menjadi suatu kelebihan dan dapat memudahkan dalam pengumpulan dan pengolahan data-data pada perangkat multi platform sehingga dapat disimpulkan bahwa aplikasi ARUMI berbasis iOS ini sudah layak untuk diperlihatkan kepada pihak perusahaan / investor untuk segera dapat segera mengumpulkan sumber daya dan tenaga pendukung untuk kemudian dapat diperkenalkan dan dapat mulai digunakan oleh masyarakat luas sebagai suatu solusi dan gaya hidup baru dalam menyelesaikan pekerjaan rumah tangga pada masyarakat modern[8]. 
TABEL 2. HASIL PENGUJANPEMESANAN LAYANAN

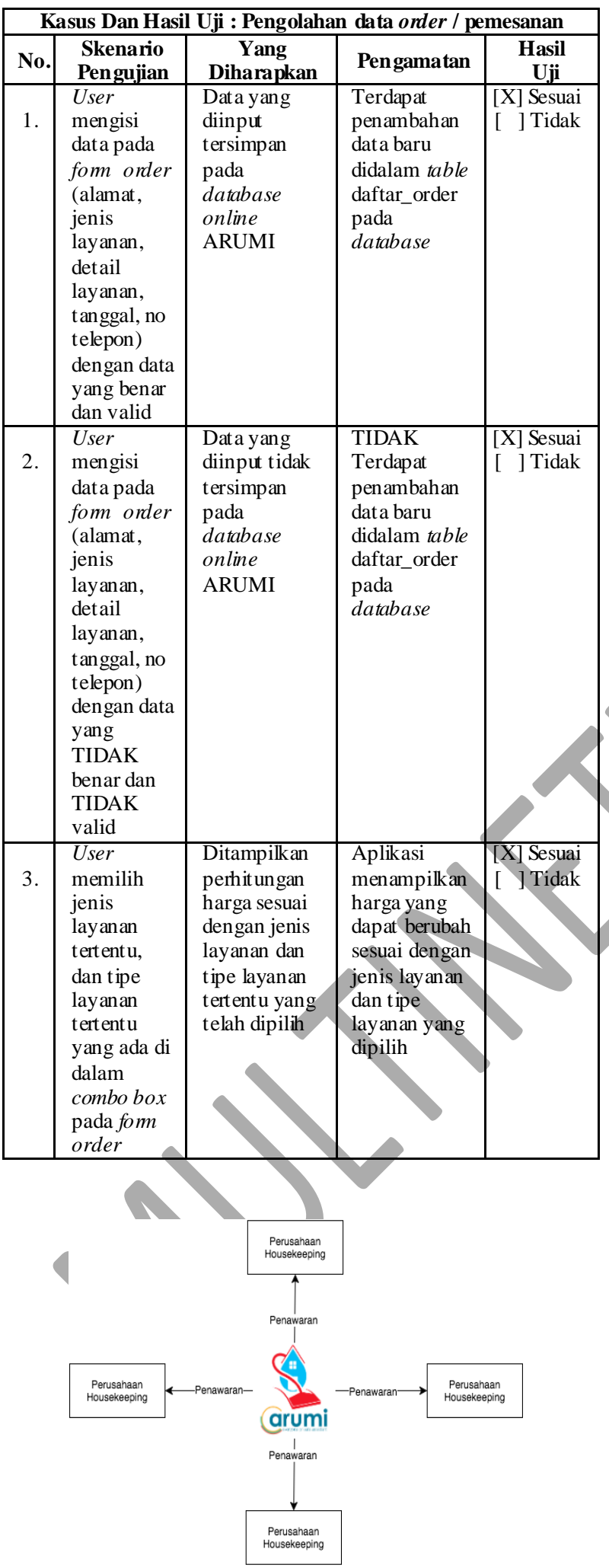

Gambar 12. Pola Penyebaran Aplikasi
TABEL 3. HASIL ANALISIS PENGUJIAN BLACKBOX

\begin{tabular}{|c|l|l|l|}
\hline No & $\begin{array}{l}\text { Kategori } \\
\text { Uji }\end{array}$ & Hasil Analisa & Ket. \\
\hline 1. & $\begin{array}{l}\text { Registrasi / } \\
\text { Sign Up }\end{array}$ & $\begin{array}{l}\text { Proses Registrasi berjalan } \\
\text { dengan baik, data yang } \\
\text { baru di input bisa } \\
\text { tersimpan ke dalam } \\
\text { database. 1 email hanya } \\
\text { dapat mendaftarkan 1 } \\
\text { akun. }\end{array}$ & $\square$ Sesuai \\
\hline 2. & Login & $\begin{array}{l}\text { Proses login berjalan } \\
\text { dengan baik, hanya user } \\
\text { yang telah terdaftar yang } \\
\text { dapat melakukan login, }\end{array}$ & $\square$ Sesuai \\
\hline 3. & $\begin{array}{l}\text { Pengolahan } \\
\text { Data }\end{array}$ & $\begin{array}{l}\text { Data dapat diproses sesuai } \\
\text { dengan input yang } \\
\text { diberikan, proses input } \\
\text { memilki validasi unt uk } \\
\text { menghindari Junk data, } \\
\text { data juga dapat terintegrasi } \\
\text { dengan database }\end{array}$ & $\square$ Sesuai \\
\hline
\end{tabular}

\section{Deployment}

Tahapan akhir dari pembuatan aplikasi menggunakan metode GRAPPLE ialah Deployment, yaitu tahapan untuk penyebaran aplikasi setelah aplikasi selesai dibuat. Penulis melakukan delivery penyebaran aplikasi ARUMI dengan cara memperlihatkan aplikasi pada perusahaanperusahaan penyedia layanan housekeeping dan membuat UAT untuk mengetahui kesesuaian hasil implementasi dengan requirement yang dibutuhkan user, khususnya pada pihak perusahaan yang sebelumnya terlibat dalam pengumpulan data requirement aplikasi, sesuai dengan Gambar 12 . Penyebaran dengan cara tersebut dinilai sangat efektif mengingat agar aplikasi ARUMI dapat digunakan oleh masyarakat sangat diperlukan sumber daya manusia yang dapat mendukung terhadap pengerjaan layanan-layanan yang ditawarkan dalam aplikasi, oleh sebab itu aplikasi tidak di-upload pada appstore karena sebelum dapat digunakan oleh masyarakat umum maka terlebih dulu diperlukan kerjasama dengan perusahaan penyedia housekeeping konvensional yang telah memiliki sumber daya manusia dan tenaga kerja pendukung. Maka, penulis memilih untuk melakukan penyebaran aplikasi dengan memperlihatkan aplikasi dan memberikan penawaran kepada perusahaan-perusahaan penyedia layanan housekeeping konvensional.

\section{KESIMPULAN DAN SARAN}

\section{A. Simpulan}

Berdasarkan hasil dan pelaporan dari tugas akhir ini, maka dapat disimpulkan bahwa aplikasi mobile housekeeping berbasis iOS yang dapat memfasilitasi perusahaan housekeeping untuk 
menawarkan layanannya kepada masyarakat umum dapat dibuat dengan cara melakukan beberapa tahapan, yaitu mengumpulkan requirement dari pelaku industri jasa housekeeping terkait, kemudian melakukan analisis untuk mengetahui konsep perancangan dari aplikasi tersebut, selanjutnya ialah membuat perancangan design yang dibuat sesuai dengan requirement yang dibutuhkan meliputi design perancangan UML dan tampilan user interface. kemudian dilakukan tahapan development yaitu melakukan implementasi koding dan konstruksi terhadap aplikasi tersebut.

Fitur-fitur yang terdapat pada aplikasi ialah pemesanan layan jasa bersih rumah, laundry, cuci motor, cuci mobil, angkut barang, dan jasa tukang. Selain itu juga terdapat fitur geolocation map, histori order dan komplain yang terdapat pada aplikasi. Sedangkan pada aplikasi petugas terdapat fitur navigasi map yang menampilkan estimasi jarak, waktu tempuh, dan rute terdekat.

Tahapan akhir dari pembuatan aplikasi ini ialah melakukan deployment dengan melakukan pengujian UAT yang melibatkan pihak perusahaan housekeeping terkait untuk memastikan bahwa aplikasi yang dibuat telah sesuai dengan requirement yang dibutuhkan oleh perusahaan terkait. Dari hasil pengujian maka dapat diketahui bahwa aplikasi telah berhasil dibuat sesuai dengan kebutuhan pihak perusahaan terkait sehingga dapat disimpulkan bahwa aplikasi ARUMI dapat digunakan untuk memfasilitasi perusahaan houskeeping dalam menawarkan layanan nya kepada masyarakat umum dan juga dapat dimanfaatkan untuk menghubungkan antara perusahaan penyedia jasa dengan masyarakat secara umu m.

\section{B. Saran}

Beberapa hal yang diharapkan dan dapat dikembangkan pada masa mendatang adalah sebagai berikut:

1. Sebelum dapat memperkenalkan aplikasi ini kepada user dan dapat digunakan user, diperlukan kerjasama dengan penyedia layanan jasa housekeeping untuk mendukung sumber daya dan tenaga pekerja housekeeping profesional.

2. Sebelum aplikasi ini dapat digunakan masyarakat luas / user maka diperlukan integrasi dengan sistem pada rekanan perusahaan penyedia layanan jasa houskeeping konvensional, meliputi integrasi data tenaga kerja, harga, layanan hingga melakukan training cara penggunaan aplikasi bagi admin dan asisten.

3. Apabila dikemudian hari aplikasi telah digunakan oleh masyarakat luas dengan traffic pertukaran transaksi data yang berjumlah besar maka diperlukan migrasi server menggunakan layanan berbayar Mobile Backend as a Service (MBaaS) pada penyedia layanan besar seperti Kinvey, Firebase, dll untuk mendukung pertukaran data dan transaksi data skala besar agar aplikasi dapat berjalan dengan cepat dan data-data dapat dijamin keamanannya.

\section{REFERENSI}

[1] https:/tekno.kompas.com/read/2015/12/21/14010037/Fac ebook.Tet ap.Menjadi.Aplikasi.Terpopuler.2015

[2] Schmuller, Joseph. 2004. Teach Yourself UML In 24 Hours 3th ed. Indianapolis: Sams Publishing.

[3] Sommerville, Ian.2011.Software Engineering Ninth Edition. Boston: Pearson.

[4] Pressman RS. 2010. Soft ware Engineering : A Practitioner's Approach, 7th ed. New York: McGraw Hill.

[5] Pressman, R. S. \& Maxim, B. R., 2015. Software Engineering : A Practitioner's Approach 8th Edition. New York: McGraw-Hill Education.

[6] Raharjo, Budi.2011.Membuat Database Menggunakan MySql. Bandung : Informatika.

[7] Salbino, Sherief. 2015. Buku Pintar iPad \& iPhone untuk Pemula. Jakarta: Kunci Komunikasi.

[8] Perry, W. 2013. Surviving the Top Ten Challenges of Software Testing: A People-Oriented Approach. New York: Pearson Education Inc. 